\title{
PENGARUH CITRA BANK, KUALITAS PELAYANAN, KEPERCAYAAN NASABAH, PENANGANAN KELUHAN, DAN KEPUASAN TERHADAP LOYALITAS NASABAH PADA BANK SUMSEL BABEL KANTOR CAPEM SYARIAH UIN RADEN FATAH PALEMBANG
}

\author{
Mail Hilian Batin 1 \\ 1,2 Universitas Islam Negeri Raden Fatah, Palembang \\ $\triangle$ mail.batin_uin@radenfatah.ac.id
}

\begin{abstract}
The purpose of this study is to determine the effect of variable bank image, service quality, customer trust, handling complaints, and satisfaction with customer loyalty. Islamic Bank SUMSEL BABEL of UIN Raden Fatah Palembang. The Source of Data taken is primary data through questionnaires to 100 respondents using purposive sampling. The results showed that the bank image variable, service quality, customer trust, and complaint handling had a simultaneous effect on customer loyalty, as evidenced by the significance value of 0,000 <0,05. While the partial test can be concluded that the bank image variable (X1) has a positive effect on customer loyalty (Y), this is evidenced by a significance value of $0.006<0.05$. Service quality variable (X2) does not affect customer loyalty $(Y)$, this is evidenced by the significance value of 0.997> 0.05. The variable customer trust (X3) has a positive effect on customer loyalty $(Y)$, this is evidenced by the significance value of $0.003<0.05$. The complaint handling variable (X4) has a positive effect on customer loyalty $(Y)$, this is evidenced by the significance value of $0.009<0.05$. Satisfaction variable (X5) has a positive effect on customer loyalty (Y), this is evidenced by the significance value of $0.021<0.05$.
\end{abstract}

Keywords : bank image, service quality, customer trust, complaint handling, customer loyalty

\section{LATAR BELAKANG}

Perkembangan bank syariah di Indonesia kini menjadi tolak ukur keberhasilan eksistensi ekonomi syariah. Krisis moneter yang terjadi pada tahun 1998 telah menenggelamkan bank-bank konvensional dan banyak dilikuidasi karena kegagalan sistem bunganya, sementara perbankan yang menerapkan sistem syariah dapat tetap eksis dan mampu bertahan hingga saat ini.Tidak hanya itu, di tengah-tengah krisis keuangan global yang melanda dunia pada ujung akhir tahun 2008, lembaga keuangan syariah kembali membuktikan daya tahannya dari terpaan krisis (Hasan, 2014). Hal inilah yang menyebabkan mengapa perbankan syariah lebih unggul dibanding bank konvensional. Keunggulan perbankan syariah disebabkan karena kenaikan suku bunga tidak akan berdampak bagi perbankan syariah contohnya produk pembiayaan. Nasabah yang melakukan pembiayaan di bank syariah cicilannya flat atau tetap hingga berakhirnya akad. 
Keunggulan perbankan syariah tentu berdampak positif bagi industry jasa keuangan syariah.Maka bermunculanlah perbankan syariah baik yang tergabung dalam Bank Umum Syariah (BUS), Unit Usaha Syariah (UUS), ataupun Bank Pembiayaan Rakyat Syariah (BPRS). Perkembangan tersebut akan menyebabkan persaingan antar perbankan. Persaingan yang ketat antar bank tersebut menimbulkan perubahan sistem dalam bisnis perbankan.Perubahan ini disebabkan karena adanya perubahan permintaan pelayanan nasabah, teknologi dan perilaku pesaing.Ketepatan strategi menjadi modal penting bagi perbankan untuk bisa mempertahankan nasabahnya agar tetap loyal (Priansa, 2016).

Salah satu bank syariah milik pemerintah daerah yaitu Bank SUMSEL BABEL Syariah. Bank SUMSEL BABEL Syariah selalu melakukan inovasi dan renovasi dari berbagai agar mampu bersaing bagi perbankan lainnya. Hal ini dilakukan semata-mata agar dapat memberikan pelayanan maksimal kepada nasabah, sehingga nasabah tersebut akan merasa loyal. Faktor-faktor yang bisa mempengaruhi loyalitas (kesetiaan) nasabah menurut Adi Krismanto adalah citra lembaga, kualitas pelayanan dan penanganan komplain. Maka dengan begitu setiap bank perlu memberikan citra bank yang positif di mata masyarakat, memberikan kualitas pelayanan yang terbaik serta menangani keluhan nasabah dengan sebaik-baiknya. Dalam hal loyalitas tidak semua nasabah Bank Sumsel Babel Syariah menunjukkan rasa loyalnya, hal ini dikarenakan fasilitas, pelayanan, produk dan penanganan komplain dari bank masih kurang memuaskan nasabah.

Salah satu aset terpenting dari suatu perusahaan adalah citra perusahaan (Soemirat dan Ardianto, 2010). Kebanyakan perusahaan juga meyakini bahwa citra perusahaan yang positif adalah sukses yang berkelanjutan dan dalam jangka panjang. Karyawan Bank Sumsel Babel Cabang Syariah yaitu Ami Lusiani selakuCustomer Serviceberpendapat bahwa,"setiap karyawan tentunya harus terus membangun dan menjaga citra positif bagi banknya, karena ketika bank telah memiliki citra yang positif, maka hal ini secara tidak langsung bisa membuat nasabah tertarik untuk bertransaksi di bank tersebut". Direktur utama Bank Sumsel Babel, Muhammad Adil menerangkan bahwa selama tahun 2017 lalu Bank Sumsel Babel Syariah membuktikan kinerjanya dengan keberhasilan meraih beberapa penghargaan yaitu Special Mention For Great Customer Service, The Most Expanding Effective Asset lebih dari Rp. 1,5 triliun dan The Most Effective Financing Sharia unit aset lebih dari Rp. 1,5 triliun (www.rmolsumsel.com, 2017).

Dengan beberapa penghargaan yang telah diraih, secara tidak langsung Bank Sumsel Babel Syariah telah berusaha memberikan citra perusahaan yang baik, tetapi pada faktanya disisi lain masih banyak sebagian nasabah bank yang menilai dan melihat bahwa citra bank tersebut masih kurang. Hal ini disebabkan karena sebagian karyawan masih kurang ramah, kurang sopan dan kurang tersenyum saat melayani nasabah sehingga hal ini bisa menurunkan citra baik bank yang telah ada dan pada akhirnya tujuan bank untuk menjaga loyalitas nasabah masih sedikit sulit untuk dicapai.

Setiap perusahaan atau Badan Usaha, kualitas pelayanan, kepuasan, dan kepercayaan merupakan faktor penting dalam membangun usaha untuk membentuk loyalitas kepada para nasabah atau konsumennya. Bila nasabah merasa tidak puas dapat menyebabkan nasabah tersebut pindah ke perusahaan lainnya, sehingga akan merugikan perusahaan tersebut. Namun dalam bisnis perbankan untuk dapat memenangkan persaingan bukan hanya dituntut untuk memberikan kualitas pelayanan yang baik saja tetapi yang lebih utama adalah bagaimana bank yang 
bersangkutan memperoleh kepuasan dan kepercayaan dari masyarakat atau nasabahnya (Tjiptono, 2014).

Bank Sumsel Babel Kantor Capem Syariah UIN Raden Fatah Palembang merupakan salah satu bank yang terletak di lingkungan kampus.Pelayanan yang prima menjadi prioritas Bank tersebut dalam menunjang keberhasilan bisnis.Hal inilah yang menurut Ami Lusiani. Selaku Costumer Service menyebutkan bahwa pada Tahun 2017 jumlah nasabah pada Bank Sumsel Babel Kantor Capem Syariah UIN Raden Fatah Palembang yaitu sebesar 75\% dari mahasiswa, 15\% dari karyawan dosen, 7\% dari masyarakat sekitar/umum dan 3\% dari karyawan bank dari persentasi 100\%. Namun setiap penerimaan mahasiswa baru pada bulan Agustus dan September produk Tabungan Rofiqoh meningkat sangat pesat sampai jumlah yang menabung 4.500 mahasiswa karna syarat dari membuat KTM harus mempunyai buku tabungan dari Bank Sumsel Babel Kantor Capem Syariah UIN Raden Fatah Palembang.

Ketepatan strategi yang digunakan menjadi syarat mutlak perusahaan dalam mencapai loyalitas menabung bagi nasabah. Keberhasilan suatu perusahaan dapat dilihat dari seberapa loyal nasabah tersebut, jika sudah loyal maka nasabah sudah pasti percaya dan puas akan lembaga jasa keuangan tersebut.

\section{TEORI DAN METODE}

\subsection{Loyalitas}

Beberapa Tahap-Tahap Loyalitas Pelanggan, sebagai berikut: (Etta Mamang dan Sopiah, 2013)

a) Terduga (suspects), meliputi semua orang yang mungkin akan membeli barang atau jasa perusahaan, tetapi sama sekali belum mengenal perusahaan dan barang atau jasa yang ditawarkan.

b) Prospek (prospects), merupakan orang-orang yang memiliki kebutuhan akan produk atau jasa tertentu dan mempunyai kemampuan untuk membelinya. Meskipun belum melakukan pembelian, para prospek telah mengetahui keberadaan perusahaan barang atau jasa yang ditawarkan karena seseorang telah merekomendasikan barang atau jasa tersebut kepadanya.

c) Prospek terdiskualifikasi (disqualified prospects), yaitu prospek yang telah mengetahui keberadaan barang atau jasa tertentu, tetapi tidak mempunyai kebutuhan akan barang/ jasa tersebut atau tidak mempunyai kemampuan untuk membeli barang atau jasa tersebut.

d) Pelanggan mula-mula (first time customers), yaitu pelanggan yang membeli untuk pertama kalinya, mereka masih menjadi pelanggan yang baru.

e) Pelanggan berulang (repeat customers), yaitu pelanggan yang telah membeli produk yang sama sebanyak dua kali atau lebih, membeli dua macam produk yang berbeda dalam dua kesempatan yang berbeda pula.

f) Klien, klien membeli semua barang atau jasa yang ditawarkan dan dibutuhkan. Mereka membeli secara teratur. Hubungan dengan jenis pelanggan ini sudah kuat dan berlangsung lama, yang membuat mereka tidak terpengaruh oleh produk pesaing.

g) Pendukung (advocates), seperti halnya klien, pendukung membeli barang atau jasa yang ditawarkan dan yang dibutuhkan serta melakukan pembelian secara teratur. Selain itu mereka mendorong teman-teman mereka agar membeli barang atau jasa perusahaan atau merekomendasikan perusahaan tersebut 
pada orang lain. Dengan begitu secara tidak langsung mereka telah melakukan pemasaran dan membawa pelanggan untuk perusahaan.

h) Mitra, merupakan bentuk hubungan yang paling kuat antara pelanggan dan perusahaan, berlangsung secara terus menerus karena kedua pihak melihatnya sebagai hubungan yang saling menguntungkan.

Beberapa Langkah-langkah dalam mengoptimalkan Loyalitas Pelanggan, sebagai berikut: (Veithzal Rivai, 2017)

a) Menanyakan kebutuhan pelanggan.

b) Berikan kualitas produk terbaik.

c) Ciptakan suasana kekeluargaan, dalam hal ini libatkanlah pelanggan dalam suatu obrolan yang ringan untuk menciptakan situasi yang nyaman.

d) Bentuk ikatan psikologis dengan cara memberikan ucapan pada momen tertentu seperti ucapan ulang tahun. Dengan demikian, pelanggan akan merasa diperhatikan.

\subsection{Citra Bank}

Citra merupakan persepsi yang terbentuk dalam benak manusia. Berikut faktor-faktor pembentuk citra menurut Syarifuddin dan Suryanto yang dikutip dalam penelitian (Sefillya Rauda, 2017):

Tabel 1 Faktor-faktor Pembentuk Citra

\begin{tabular}{|c|c|}
\hline Variabel & Indikator \\
\hline \multirow{3}{*}{ Identitas Fisik } & 1. Karakteristik gedung bank \\
\hline & 2. Logo dan warna bank \\
\hline & 3. Karakteristik gedung bank \\
\hline \multirow{3}{*}{ Identitas Non Fisik } & 1. Budaya yang diterapkan oleh bank \\
\hline & 2. Kinerja dan tingkat keamanan bank \\
\hline & $\begin{array}{l}\text { 3. Sikap tanggung jawab yang dimiliki } \\
\text { bank }\end{array}$ \\
\hline \multirow[t]{3}{*}{ Kualitas Hasil } & $\begin{array}{l}\text { 1. Kualitas produk atau jasa yang } \\
\text { dimiliki bank }\end{array}$ \\
\hline & 2. Desain produk atau jasa bank \\
\hline & 3. Variasi produk atau jasa bank \\
\hline \multirow[t]{2}{*}{ Aktivitas dan Pola Hubungan } & $\begin{array}{l}\text { 1. Sikap ramah tamah yang diberikan } \\
\text { karyawan bank }\end{array}$ \\
\hline & $\begin{array}{l}\text { 2. Kepedulian karyawan bank } \\
\text { terhadap kebutuhan nasabah }\end{array}$ \\
\hline
\end{tabular}

\subsection{Kualitas Pelayanan}

Beberapa dimensi kualitas jasa, yaitu: (Etta Mamang, 2013)

a) Keandalan (reliability), yaitu kemampuan untuk memberikan pelayanan yang dijanjikan dengan tepat dan kemampuan untuk dipercaya, terutama memberikan jasa secara tepat waktu dengan cara yang sama sesuai dengan jadwal yang telah dijanjikan dan tanpa melakukan kesalahan.

b) Daya tanggap (responsiveness), yaitu kemauan atau keinginan para karyawan untuk membantu memberikan jasa yang dibutuhkan konsumen.

c) Jaminan (assurance), meliputi pengetahuan, kemampuan, keramahan, kesopanan dan sifat dapat dipercaya dari kontak personal untuk 
menghilangkan sifat keragu-raguan konsumen dan membuat mereka merasa terbebas dari bahaya dan risiko.

d) Empati, yang meliputi sikap kontak personal atau perusahaan untuk memahami kebutuhan dan kesulitan konsumen, komunikasi yang baik, perhatian pribadi dan kemudahan untuk melakukan komunikasi atau hubungan.

e) Produk-produk fisik (tangibles), tersedianya fasilitas fisik, perlengkapan dan sarana komunikasi.

\subsection{Kepercayaan}

Kepercayaan adalah perasaan percaya pihak tertentu terhadap yang lain dalam melakukan relationship transaksi berdasarkan suatu keyakinan bahwa orang yang dipercayainya tersebut memiliki segala kewajibannya secara baik yang sesuai yang diharapkan. Kepercayaan merupakan hal penting bagi kesuksesan relationship. Relationship Benefit (Priansa, 2013).

Beberapa Faktor-faktor yang Mempengaruhi Kepercayaan Nasabah, yaitu:

a) Nilai merupakan hal mendasar untuk mengembangkan kepercayaan. Pihakpihak dalam relationship yang memiliki perilaku, tujuan dan kebijakan yang sama akan mempengaruhi kemampuan mengembangkan kepercayaan.

b) Ketergantungan pada pihak lain mengimplikasikan kerentanan. Untuk mengurangi resiko pihak yang tidak percaya akan membina relitionship dengan pihak yang dapat dipercaya.

c) Komunikasi yang terbuka dan teratur, komunikasi yang dilakukan untuk menghasilkan kepercayaan harus dilakukan secara teratur dan berkualitas tinggi atau dengan kata lain harus relevan dan tepat waktu. Komunikasi masa lalu yang positif akan menimbulkan kepercayaan dan pada gilirannya menjadi kemunikasi yang lebih baik.

Beberapa Indikator kepercayaan menurut (Fandy Tjiptono, 2013), yaitu:

a) Brand Reliability, meliputi jasa yang sesuai dengan harapan, kepercayaan pada produk danjaminan kepuasan.

b) Brand Intentions, kejujuran dalam menyelesaikan masalah, konsumen yang mengandalkan produk yang digunakan dan jaminan ganti rugi dari pihak perusahaan.

\subsection{Penanganan Keluhan Nasabah}

Secara sederhana, komplain bisa diartikan sebagai ungkapan ketidakpuasan atau kekecewaan. Organisasi bisa mengumpulkan komplain pelanggan melalui sejumlah cara, diantaranya kotak saran, formulir komplain pelanggan, saluran telepon khusus, website, kartu komentar, survei kepuasan pelanggan dan customer exit surveys (Fandy Tjiptono, 2013)

Keluhan pelanggan merupakan ungkapan emosional pelanggan karena adanya sesuatu yang tidak dapat diterimanya, baik yang berkaitan dengan produk yang ditawarkan maupun dengan pelayanan. Jadi dapat disimpulkan bahwa penanganan keluhan adalah permasalahan dari nasabah bank yang harus ditanggapi dan ditangani secara cepat dan tepat oleh karyawan bank.

Secara lebih mendetail, langkah atau proses untuk mengatasi keluhan pelanggan adalah sebagai berikut: (Fandy Tjiptono, 2013)

a) Mendengarkan secara aktif.

b) Meminta maaf atau berempati. 
c) Memahami situasi.

d) Memberi informasi.

e) Menawarkan bantuan.

f) Menawarkan alternatif pemecahan.

g) Mendapatkan persetujuan pelanggan.

h) Mengambil tindakan.

i) Meminta maaf atau menyampaikan terima kasih.

j) Menindaklanjuti.

\subsection{Kepuasan Nasabah}

Kata kepuasan atau satisfaction berasal dari bahasa latin "satis" (artinya cukup baik, memadai) dan "facio" (melakukan atau membuat). Secara sederhana kepuasan dapat diartikan sebagai upaya pemenuhan sesuatu yang memadai (Rambat, 2013).

Kepuasan nasabah yaitu tingkat perasaan dimana seseorang menyatakan hasil perbandingan atas kinerja produk atau jasa yang diterima sesuai yang diharapkan. (Donii Juni, 2016)

Menurut (Rambat Lupiyoadi, 2008) menyatakan dalam menentukan tingkat kepuasan nasabah terdapat 5 dimensi atribut faktor utama yang harus diperhatikan bank atau perusahaan yaitu :

a) Kualitas Produk

Pelanggan akan merasa puas bila hasil evaluasi menunjukan bahwa produk yang digunakan berkualitas.

b) Kualitas Pelayanan

Terutama untuk industri jasa, nasabah akan merasa puas bila mereka mendapatkan pelayanan yang baik atau yang sesuai dengan yang diharapkan.

c) Emosional

Nasabah akan merasa bangga dan mendapatkan keyakinan bahwa orang lain akan kagum terhadap dia bila menggunakan produk dengan merek terutama yang senderung mempunyai tingkat kepuasan yang lebih tinggi.

d) Harga

Produk yang mempunyai kualitas yang sama tetapi menetapkan harga yang relatif murah akan memberikan nilai yang lebih tinggi kepada nasabahnya.

e) Biaya

Nasabah yang tidak perlu mengeluarkan biaya tambahan atau tidak perlu membuang waktu untuk mendapatkan suatu produk atau jasa cenderung puas terhadap produk atau jasa itu. berikut:

Berdasarkan Teori di atas, dapat digambarkan model penelitiannya sebagai

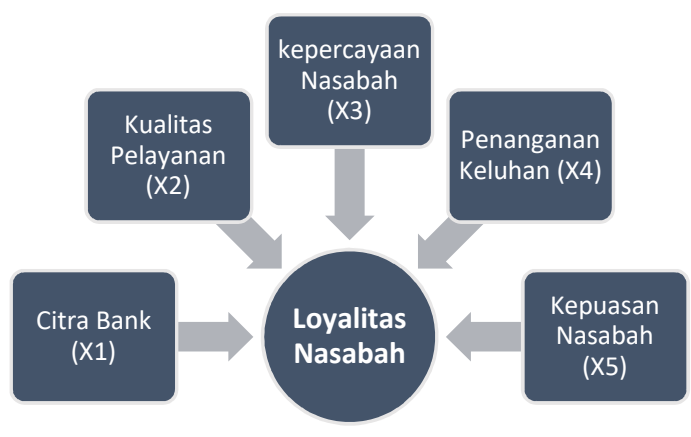

Gambar 1: Model Penelitian 
Dirumuskan hipotesis sebagai berikut:

Ho : Diterima jika Citra Bank, Kualitas Pelayanan, Keprcayaan Nasabah, Penanganan Keluhan, dan Kepuasan Nasabah ada pengaruh signifikan terhadap Loyalitas Nasabah

Ha : Ditolak jika Citra Bank, Kualitas Pelayanan, Keprcayaan Nasabah, Penanganan Keluhan, dan Kepuasan Nasabah tidak ada pengaruh signifikan terhadap Loyalitas Nasabah

\subsection{Metode Penelitian}

Penelitian ini menggunakan metode kuantitatif. Sumber pengambilan data yaitu primer dengan menggunakan kuesioner.Penyeberan kuesioner dilakukan sebanyak 100 respon nasabah penabung dengan lama menabung minimal 6-12 bulan. Penentuan jumlah sampel menggunakan rumus slovin dan purposive sampling (ditentukan). Langkah pengujian pertama yaitu kelayakan instrumen kuesioner yaitu validitas dan reliabilitas, kemudian melakukan uji asumsi klasik: uji normalitas, linieritas, multikolonieritas, dan heteroskedastisitas.Model yang digunakan yaitu analisis regresi linier berganda.Bentuk persamaanya yaitu sebagai berikut:

$$
\mathrm{Y}=\mathrm{a}+\mathrm{b}_{1} \mathrm{X}_{1}+\mathrm{b}_{2} \mathrm{X}_{2}+\mathrm{b}_{3} \mathrm{X}_{3}+\mathrm{b}_{4} \mathrm{X}_{4}+\mathrm{b}_{5} \mathrm{X}_{5}+\mathrm{e}
$$

Keterangan:

Y= Loyalitas Nasabah

$\mathrm{a}=$ Konstanta

$\mathrm{b}_{1}=$ Koefisien Regresi variabel Citra Bank

$\mathrm{X}_{1}=$ Citra Bank

$\mathrm{b}_{2}=$ Koefisien Regresi variabel Kualitas Pelayanan

$\mathrm{X}_{2}=$ Kualitas Pelayanan

$\mathrm{b}_{3}=$ Koefisien Regresi Variabel Kepercayaan Nasabah

$\mathrm{X}_{3}=$ Kepercayaan Nasabah

$\mathrm{b}_{4}=$ Koefisien Regresi Variabel Penanganan Keluhan

$\mathrm{X}_{4}=$ Penanganan Keluhan

$\mathrm{b}_{5}=$ Koefisien Regresi Variabel Kepuasan Nasabah

$\mathrm{X}_{5}=$ Kepuasan Nasabah

$\mathrm{e}=$ error

Pengolahan data menggunakan aplikasi SPSS V.20.Pengujian dilakukan dengan melihat uji Simultan (uji-F), uji Parsial (uji-t), dan Uji Koefisien Determinasi (Adjusted $\mathrm{R}^{2}$ ).

\section{HASIL DAN PEMBAHASAN}

\subsection{Karakteristik Responden}

a) Jenis Kelamin

Tabel 2 Jenis Kelamin Nasabah

\begin{tabular}{llrrrr}
\hline & & Frequency & Percent & Valid Percent & Cumulative Percent \\
\hline Valid & laki-laki & 44 & 44,0 & 44,0 & 44,0 \\
& Perempuan & 56 & 56,0 & 56,0 & 100,0 \\
& Total & 100 & 100,0 & 100,0 & \\
\hline
\end{tabular}

Sumber : Data Primer yang diolah, 2018. 
Berdasarkan table di atas bahwa jenis kelamin responden nasabah Bank Sumsel Babel menunjukkan bahwa mayoritas responden ialah perempuan berjumlah 56 orang, sedangkan responden laki-laki sebanyak 44 orang. Hal ini menunjukkan bahwa sebagian besar dari nasabah Bank Sumsel Babel ialah perempuan.

b) Pekerjaan

Tabel 3 Jenis Pekerjaan

\begin{tabular}{llrrrr}
\hline & Frequency & Percent & Valid Percent & Cumulative Percent \\
\hline Valid & pelajar/mahasiswa & 46 & 46,0 & 46,0 & 46,0 \\
Pegawai Negeri & 26 & 26,0 & 26,0 & 72,0 \\
(PNS) & 12 & 12,0 & 12,0 & 84,0 \\
Karyawan & & 16 & 16,0 & 16,0 & 100,0 \\
Lain-lain & 100 & 100,0 & 100,0 \\
\cline { 2 - 5 }
\end{tabular}

Sumber : Data Primer yang diolah, 2018.

Berdasarkan table tersebut memperlihatkan bahwa nasabah Bank Sumsel Babel sebagian besar adalah Mahasiswa sebanyak 46 orang, Pegawai Negeri (PNS) adalah 26 orang, Karyawan adalah 12 orang, dan lain-lain adalah 16 orang.

c) Lama Menjadi Nasabah

Tabel 4 Lama menjadi Nasabah

\begin{tabular}{rrrrrr}
\hline & Frequency & Percent & Valid Percent & Cumulative Percent \\
\hline Valid & 6 bulan- 1 tahun & 39 & 39,0 & 39,0 & 39,0 \\
& $>1$ tahun & 61 & 61,0 & 61,0 & 100,0 \\
\cline { 2 - 5 } & Total & 100 & 100,0 & 100,0 & \\
\hline
\end{tabular}

Sumber : Data Primer yang diolah, 2018.

Tabel di atas memperlihatkan bahwa yang menjadi nasabah Bank rentang waktu 6 bulan hingga 1 tahun sebanyak 61 orang, dan $>1$ tahun adalah sebanyak 39 orang. Hal ini menunjukkan bahwa nasabah yang menabung di Bank Sumsel Babel Kantor Capem Syariah UIN Raden Fatah Palembang di atas rata-rata $>1$ tahun.

d) Jumlah uang ditabung selama 1 bulan

Tabel 5 Jumlah Uang Ditabung

\begin{tabular}{rlrrrr}
\hline & Frequency & Percent & Valid Percent & Cumulative Percent \\
\hline Valid & $<$ Rp.150.000 & 32 & 32,0 & 32,0 & 32,0 \\
Rp. 200.000 & 21 & 21,0 & 21,0 & 53,0 \\
500.000 & 47 & 47,0 & 47,0 & 100,0 \\
& $>$ Rp.500.000 & 100 & 100,0 & 100,0 & \\
\hline Total & & &
\end{tabular}

Sumber : Data Primer yang diolah, 2018. 
Hasil table di atas memperlihatkan banyaknya uang yang ditabung oleh nasabah dalam 1 bulan mulai dari < Rp.150.000 adalah 32 orang, Rp.200.000 Rp.500.000 adalah 21 orang, dan > Rp.500.000 adalah 47 orang. Dapat disimpulkan bahwa jumlah uang nasabah yang ditabung dalam waktu 1 bulan > 500.000 .

e) Melakukan Pinjaman di bank

Tabel 6 Jenis Aktivitas Nasabah

\begin{tabular}{llrrrr}
\hline & Frequency & Percent & Valid Percent & Cumulative Percent \\
\hline Valid & Tabungan & 64 & 64,0 & 64,0 & 64,0 \\
& 36 & 36,0 & 36,0 & 100,0 \\
\cline { 2 - 5 } Pinjaman & 100 & 100,0 & 100,0 & \\
$\begin{array}{l}\text { Total Tabungan } \\
\text { dan Pinjaman }\end{array}$ & & &
\end{tabular}

Sumber : Data Primer yang diolah, 2018.

Berdasarkan hasil tersebut memperlihatkan bahwa nasabah yang pernah melakukan pinjaman sebanyak 36 orang, dan yang melakukan tabungan sebanyak 64 orang.Jadi hal ini menunjukkan bahwa nasabah banyak melakukan aktivitas tabungan sebanyak 64 orang.

\subsection{Hasil Uji Instrumen Penelitian}

a) Uji Validitas

Berdasarkan uji validitas, bahwa semua instrumen pertanyaan kuesioner dari varibael Citra Bank, Kualitas Pelayanan, Kepercayaan Nasabah, Penanganan Keluhan dan Kepuasan Nasabah memiliki nilai Person Correlation $>r_{\text {tabel }}$ $(0,1966)$.

b) Uji Reliabilitas

Adapun hasil dari uji reliabilitas adalah sebagai berikut:

Tabel 7 Hasil Uji Reliabilitas

\begin{tabular}{lccc}
\hline \multicolumn{1}{c}{ Variabel } & Cronbach's Alpha & Nilai Kritis & Keterangan \\
\hline Citra Bank & 0,799 & 0,60 & Reliabel \\
Kualitas Pelayanan & 0,933 & 0.60 & Reliabel \\
Kepercayaan Nasabah & 0,781 & 0,60 & Reliabel \\
Penanganan Keluhan & 0,839 & 0,60 & Reliabel \\
Kepuasan Nasabah & 0,740 & 0,60 & Reliabel \\
Loyalitas Nasabah & 0,714 & 0,60 & Reliabel \\
\hline
\end{tabular}

Sumber : Data Primer yang diolah, 2018.

Berdasarkan hasil uji reliabilitas di atas, dapat disimpulkan bahwa semua variabel bebas reliabel karena Cronbach Alfa > 0,60. 


\subsection{Hasil Analisis Data}

a) Uji Asumsi Klasik

1) Uji Normalitas

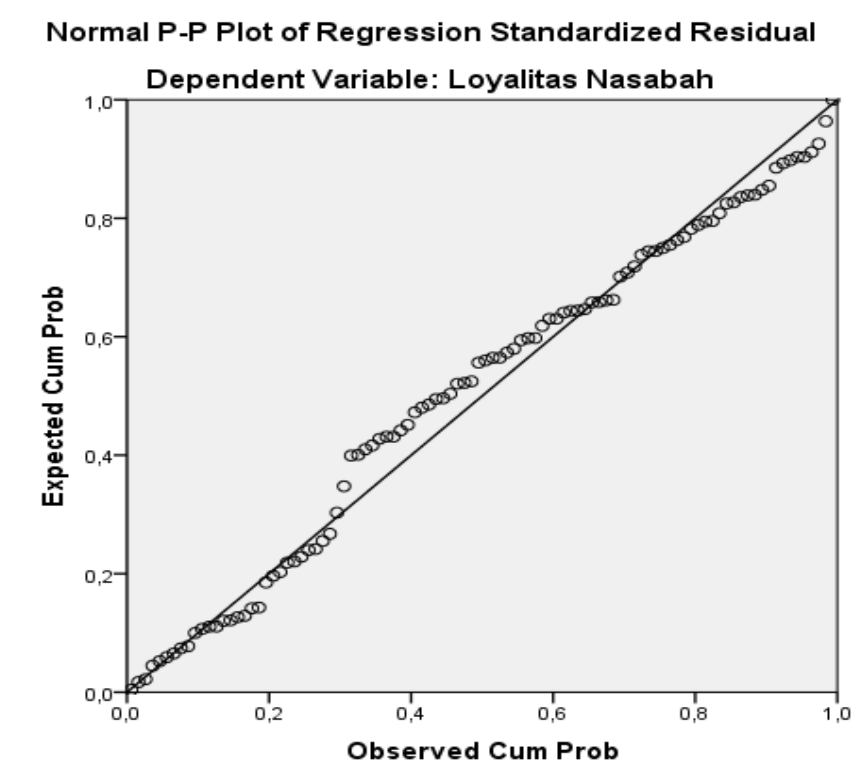

Gambar 2: Gambar P-Plot

Tabel 8 Hasil Uji K-S

\begin{tabular}{ccc}
\hline $\mathrm{N}$ & Kolmogorov-Smirnov & Sig. \\
\hline 100 & 088 & 055 \\
\hline
\end{tabular}

Berdasarkan pada grafik normal P-P Plot menunjukkan penyebaran data mengikuti garis normal (garis lurus) dan hal yang sama itu pun ditunjukkan pada pengujian Kolmogorov-Smirnov menunjukkan bahwa data yang didapat terdistribusi normal, berdasarkan hasil output menunjukkan nilai Kolmogorov-Smirnov signifikanpada 0,055 $>0,088$ maka dapat disimpulkan bahwa data residual terdistribusi normal dan model regresi telah memenuhi asumsi normalitas.

2) Uji Linieritas

Tabel 9 Uji Linearitas Citra Bank dan Loyalitas Nasabah

\begin{tabular}{ccc}
\hline & Sig. \\
\hline Loyalitas Nasabah*Citra Bank & Linearity & 0,000 \\
\hline Sumber: Data diolah, 2018 &
\end{tabular}

Berdasarkan tabel di atas diperoleh nilai signifikansi pada linearity sebesar $0,000<0,05$, maka dapat disimpulkan bahwa antara variabel citra bank dan loyalitas nasabah terdapat hubungan yang linear.

Tabel 10 Uji Linieritas Kualitas Pelayanandan Loyalitas Nasabah

\begin{tabular}{lc}
\hline & Sig. \\
\hline Loyalitas Nasabah * Kualitas Pelayanan &, 072 \\
Linearity Deviation From Linearity &, 485 \\
\hline
\end{tabular}

Sumber : Data Primer yang diolah, 2018. 
Berdasarkan tabel diatas diperoleh nilai sig. Linearity sebesar 0,485 >a $=0,005$, artinya regresi linier dapat dipergunakan untuk menjelaskan pengaruh antara kualitas pelayanan terhadap loyalitas nasabah.

Tabel 11 Uji Linieritas Kepercayaan Nasabah dan Loyalitas Nasabah

\begin{tabular}{lc}
\hline & Sig. \\
\hline Loyalitas Nasabah * Kepercayaan Nasabah &, 000 \\
Linearity Deviation From Linearity &, 340 \\
\hline
\end{tabular}

Sumber : Data Primer yang diolah, 2018.

Berdasarkan tabel diatas diperoleh nilai sig. Linearity sebesar 0,340 >a $=0,005$, artinya regresi linier dapat dipergunakan untuk menjelaskan pengaruh antara kepercayaan terhadap loyalitas nasabah.

Tabel 12 Uji Linearitas Penanganan Keluhan dan Loyalitas Nasabah

\begin{tabular}{ccc}
\hline & & Sig. \\
\hline Loyalitas Nasabah*Penanganan Keluhan & Linearity & 0,000 \\
\hline Sumber: Data diolah, 2018 &
\end{tabular}

Berdasarkan tabel di atas diperoleh nilai signifikansi pada linearity sebesar $0,000<0,05$, maka dapat disimpulkan bahwa antara variabel penanganan keluhan dan loyalitas nasabah terdapat hubungan yang linear.

Tabel 13 Hasil Uji Linieritas Loyalitas Nasabah dan Kepuasan

\begin{tabular}{lc}
\hline & Sig. \\
\hline Loyalitas Nasabah * Kepuasan &, 025 \\
Linearity Deviation From Linearity &, 283 \\
\hline
\end{tabular}

Sumber : Data Primer yang diolah, 2018.

Berdasarkan tabel diatas diperoleh nilai sig. Linearity sebesar 0,283 >a $=0,005$, artinya regresi linier dapat dipergunakan untuk menjelaskan pengaruh antara kepuasan terhadap loyalitas nasabah.

3) Uji Multikoliniearitas

Tabel 14 Hasil Uji Multikolonieritas

\begin{tabular}{llcc}
\hline \multirow{2}{*}{ Model } & \multicolumn{2}{c}{ Collinearity Statistics } \\
\cline { 2 - 3 } & Tolerance & VIF \\
\hline 1 (Constant) & .574 & 1.742 \\
Citra Bank &, 927 & 1.079 \\
kualitas pelayanan &, 946 & 1.057 \\
kepercayaan & .495 & 2.018 \\
nasabah &, 892 & 1.121 \\
Penanganan Keluhan & .125 \\
Kepuasan &
\end{tabular}


Dari hasil pengujian multikolinearitas yang dilakukan diketahui bahwa nilai variance inflation factor (VIF) kedua Variabel, apabila nilai tolerance> 0,10 dan VIF $<10$ maka tidak ada multikoliniearitas.

4) Uji Heteroskedastisitas

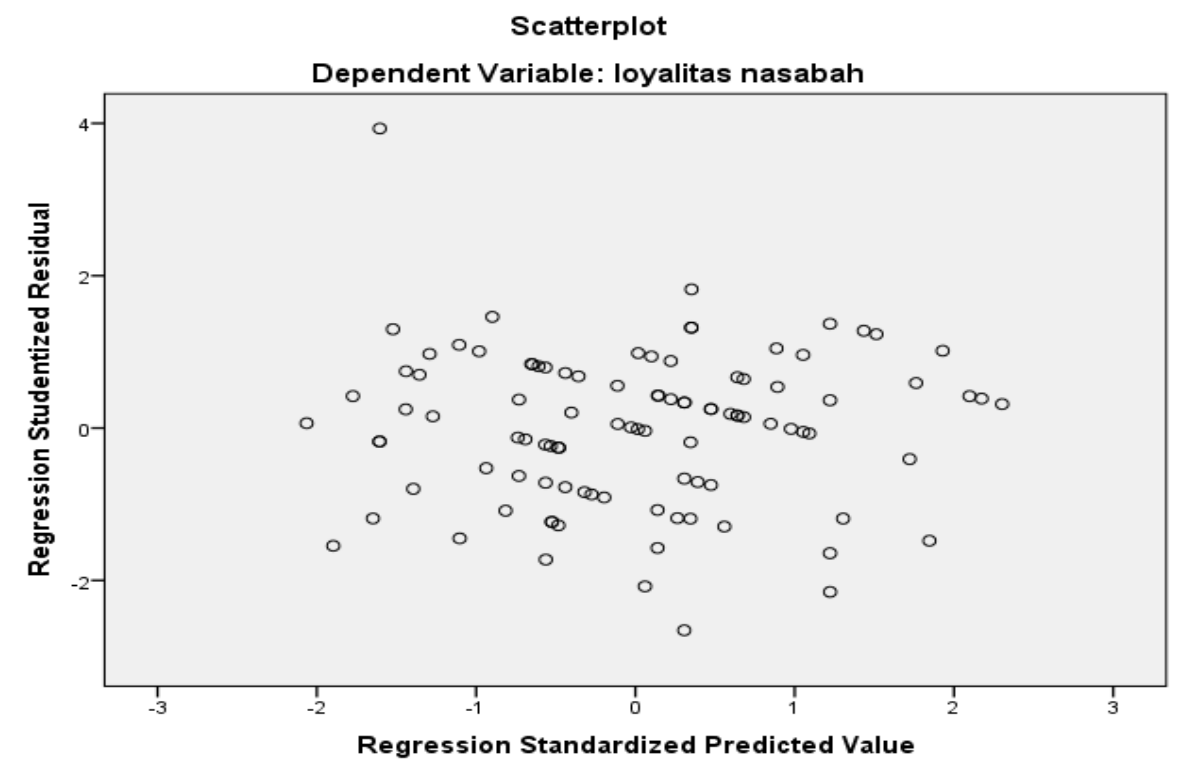

Gambar 3: Uji Scatterplot

Berdasarkan hasil uji yang dilihat bahwa titik-titik pada gambar tersebut menyebar baik diatas maupun dibawah dibawah angka 0 dan sumbu Y, maka dapat disimpulkan bahwa tidak terjadi masalah heteroskedastisitas.

\subsection{Uji Hipotesis}

a) Koefisien Determinasi $\left(\mathrm{R}^{2}\right)$

Tabel 15 Hasil Uji Koefisien Determinasi

\begin{tabular}{ccccc}
\hline Model & $\mathrm{R}$ & R Square & $\begin{array}{c}\text { Adjusted R } \\
\text { Square }\end{array}$ & $\begin{array}{c}\text { Std. Error of the } \\
\text { Estimate }\end{array}$ \\
\hline 1 &, $921^{\mathrm{a}}$ &, 847 &, 843 & 1.16812 \\
\hline
\end{tabular}

Dari tabel diatas hasil nilai koefisien determinasi (R Square) diketahui pengaruh dari kelima variabel independen (Citra Bank, Kualitas Pelayanan, Kepercayaan Nasabah, Penanganan Keluhan, dan Kepuasan) terhadap dependen (Loyalitas Nasabah) dinyatakan dalam nilai R Square yaitu 0,847 atau $84,7 \%$. Artinya 84,7\% variabel Loyalitas Nasabah bisa dijelaskan oleh ketiga variabel independen dalam penelitian tersebut.

b) Uji F (Simultan)

\begin{tabular}{llrcc}
\multicolumn{5}{c}{ Tabel 16 Hasil Uji F } \\
\hline Model & \multicolumn{1}{c}{ df } & F & Sig. \\
\hline \multirow{2}{*}{1} & Regression & 3 & 13.984 & $.000^{\text {a }}$ \\
\cline { 2 - 5 } & Residual & 96 & & \\
\cline { 2 - 5 } & Total & 99 & & \\
\hline
\end{tabular}


Berdasarkan table di atas dapat diketahui bahwa nilai $F_{\text {hitung }}$ adalah sebesar 13,984. Artinya $F_{\text {hitung }}>F_{\text {tabel }}$ yaitu $13,984>2,70$ dengan tingkat signifikansi $0,000<0,05$. Hal ini dapat disimpulkan bahwa variabel Citra Bank, Kualitas Pelayanan, Kepercayaan Nasabah, Penanganan Keluhan, dan Kepuasan berpengaruh secara simultan terhadap loyalitas nasabah.

c) Uji t (Parsial)

Tabel 17 Hasil Uji t

\begin{tabular}{|c|c|c|c|c|c|c|}
\hline \multirow{2}{*}{\multicolumn{2}{|c|}{ Model }} & \multicolumn{2}{|c|}{$\begin{array}{l}\text { Unstandardized } \\
\text { Coefficients }\end{array}$} & \multirow{2}{*}{$\begin{array}{c}\text { Standardized } \\
\text { Coefficients } \\
\text { Beta }\end{array}$} & \multirow[b]{2}{*}{$\mathrm{T}$} & \multirow[b]{2}{*}{ Sig. } \\
\hline & & B & Std. Error & & & \\
\hline \multirow[t]{6}{*}{1} & (Constant) & 6.053 & 3.384 & & 1.789 & .077 \\
\hline & Citra Bank & .268 & .095 & .316 & 2.814 & .006 \\
\hline & Kualitas Pelayan & ,144 & ,022 & ,536 & 6,440 & ,000 \\
\hline & $\begin{array}{l}\text { Kepercayaan } \\
\text { Nasabah }\end{array}$ & 219 & ,071 & ,243 & 3,092 & ,003 \\
\hline & $\begin{array}{l}\text { Penanganan } \\
\text { Keluhan }\end{array}$ & .680 & .254 & .324 & 2.676 & .009 \\
\hline & Kepuasan & 195 & ,083 & 109 & 2,343 & ,021 \\
\hline
\end{tabular}

Berdasarkan tabel perhitungan di atas, dapat disimpulkan bahwa terdapat pengaruh positif dan signifikan antara variabel citra bank, kualitas pelayanan, kepercayaan nasabah, penanganan keluhan dan kepuasan terhadap loyalitas. Hal tersebut dibuktikan dengan nilai signifikansi berada di atas 0,05 artinya menolak Ho dan menerima Ha.

\section{PENUTUP}

Hasil penelitian ini menunjukkan bahwa secara uji simultan dan parsial, semua variabel yang diajukan (Citra Bank, Kualitas Pelayanan, Kepercayaan Nasabah, Penanganan Keluhan, dan Kepuasan) berpengaruh secara positif signifikan terhadap loyalitas nasabah bank dengan nilai koefisien determinasi sebesar 84,7\%.

Saran yang dapat dijadikan masukan bagi Bank SUMSEL BABEL Kantor CAPEM Syariah UIN Raden Fatah Palembang yaitu selalu menjaga dan mempertahankan citra bank, kualitas pelayanan, kepercayaan nasabah, penanganan keluhan, dan kepuasan. Jika semua variabel ini dijaga bukan tidak mungkin nasabah potensial yang ada di UIN akan loyal dan tidak akan berpaling ke bank lain. Masukan selanjutnya yaitu mengutamakan pelatihan skill atau kompetensi kepada para karyawan agar menguasai produk-produk bank syariah, sehingga nantinya Bank SUMSEL BABEL Syariah akan menjadi tolak ukur bagi perbankan syariah yang benar-benar menerapkan prinsip syariah kemudian bisa membuka cabang di Provinsi lainnya. 


\section{DAFTAR PUSTAKA}

Adam, Muhammad. (2015). Pemasaran Jasa, Bandung: Alfabeta. (2008). Manajemen Pemasaran, Jakarta:Salemba Empat.

Donni, Priansa Juni. (2013). Prilaku Konsumen Dalam Persaingan Bisnis Kontemporer, Alfabeta Bandung.

Elvinaro, Uvi. (2015). "Pengaruh Kualitas Layanan dan Kepercayaan terhadap Loyalitas Anggota Baitul Maal Wat Tamwil (BMT) Surya Barokah", Skripsi, Palembang: Fakultas Ekonomi dan Bisnis Islam UIN Raden Fatah.

Falvian dan Guinaliu, (2007) Miasare on web usabilit websit, Journal of Computer Information System48 no 1.

Hafidudin, Didin dan Tanjung, Hendri. (2003). Manajemen Pemasaran Syariah dalam Praktik, Jakarta: Gema Insani Inpress.

Hasan, Nurul Ichsan. (2014). Perbankan Syariah (Sebuah Pengantar), Jakarta: GP Press Group.

Lupiyoadi, Rambat. (2013). Manajemen Pemasaran Jasa, Jakarta:Salemba Empat.

Nuraini, Alifah. "Pengaruh Citra, Pelayanan, Aksesoris Jasa, Keragaman Produk dan Nilai Nasabah terhadap loyalitas Nasabah (Studi pada Nasabah BPD DIY Syariah Yogyakarta)", Jurnal Ekonomi dan Bisnis Islam, Vol. IX, No. 1: 67-82. Ejournal.uinsuka.ac.id/syariah/Ekbisi/article/download/364/341

Priansa, Donii Juni. Perilaku Konsumen Dalam Persaingan Binis Kontemporer, Bandung: Alfabeta, 2016.

Purbo, Onno W dan Muhammad (2004). Etika Bisnis Islami, Yogyakarta: Unit Penerbit dan Percetakan Akademi Manajemen Perusahaan YKPN.

Rauda, Sefillya. (2017). “Pengaruh Citra Perusahaan terhadap Keputusan Mengguakan Produk Jasa Keuangan pada PT. Bank Negara (Persero) TBK. Cabang Syariah Palembang", Skripsi, (Palembang: Fakultas Ekonomi dan Bisnis Islam UIN Raden Fatah, 2017.

Salma, Fitria Salahika dan Ratnasari, Ririn Tri. "Pengaruh Kualitas Jasa Perspektif Islam terhadap Kepuasan dan Loyalitas Pelanggan Hotel Grand Kalimas di Surabaya", Jurnal Ekonomi Syariah Teori dan Terapan, Vol. 2, No. 4,2015: 322-339.https://ejournal.unair.ac.id/index.php/IESTT/article/view/574.

Sangadji, Etta Mamang dan Sopiah, (2013). Perilaku Konsumen, Yogyakarta: C.V Andi Offset.

Satriyanti, Evi Okatviani. "Pengaruh Kualitas Layanan, Kepuasan Nasabah dan Citra Bank terhadap Loyalitas Nasabah Bank Muamalat di Surabaya", Journal of Business and Banking, Vol. 2, No. 2: 171-184. https://journal.perbanas.ac.id/index.php/jbb/article/view/172.

Soemirat, Soleh dan Ardianto, Elvinaro. (2010). Dasar-Dasar Public Relation, Bandung: PT. Remaja Rosdakarya.

Sunyoto, Danang. (2014). Konsep Dasar Riset Pemasaran Dan Perilaku Konsumen,Yogyakarta: CAPS (Center for Academic Publishing Service).

Tjiptono, Fandy. Pemasaran Jasa, Yogyakarta: Bayumedia Publishing, 2014. www.rmolsumsel.com./read/2018/01/0385487/1/Torehan-Prestasi-BankSumselBabel-Syariah-2017.

Zainal, Veithzal Rivai, dkk. (2017). Islamic Marketing Management, Jakarta: PT. Bumi Aksara. 